\title{
On the formation of intermetallic matrix composites produced by mechanical alloying and sputtering
}

\author{
F. Neves ${ }^{a}$, N. Duarte ${ }^{b}$, B. Trindade ${ }^{b, *}$ \\ a INETI, DMTP, Estrada do Paço do Lumiar 22, 1649-038 Lisboa, Portugal \\ ${ }^{\mathrm{b}}$ ICEMS, Mechanical Engineering Department of Coimbra University, \\ Rua Luis Reis Santos, 3030-788 Coimbra, Portugal
}

Available online 27 September 2006

\begin{abstract}
(Ti-48Al)-based intermetallics were synthesized by a combination of mechanical alloying, sputtering and hot isostatic pressure techniques. Blended elemental powders of $\mathrm{TiH}_{2}$ and $\mathrm{Al}$ with nominal composition $\mathrm{TiH}_{2}-48 \mathrm{Al}$ were mechanically alloyed for different periods of time. The powders were then coated with $\mathrm{Ti}$ and $\mathrm{Ag}$ and subsequently hot isostatically pressed at $900{ }^{\circ} \mathrm{C}$ with a maximum pressure of $150 \mathrm{MPa}$ for $2 \mathrm{~h}$. Finally they were heat treated at $1200^{\circ} \mathrm{C}$ for $4 \mathrm{~h}$. After processing, the compacts obtained from the $\mathrm{TiH}_{2}-48 \mathrm{Al}$ coated powders had a lower hardness but a higher Young's modulus and fracture-toughness than the uncoated compacts. Therefore, the combined used of mechanical alloying, sputtering and compaction techniques might be an alternative method for the synthesis of compacts with non-conventional microstructures, formed by surface modified intermetallic particles.
\end{abstract}

(C) 2006 Elsevier B.V. All rights reserved.

Keywords: Ti-Al intermetallics; Mechanical alloying; Vapor deposition; Powder metallurgy; Mechanical properties

\section{Introduction}

The powder metallurgy (PM) route is the most commonly used method for the preparation of discontinuous reinforced metal or intermetallic matrix composites. Mechanical alloying (MA) has been used as a primary synthesis technique to produce mixtures with intermetallic compositions from elemental alloy powders. Cold pressing followed by sintering or hot isostatic pressing (HIP) can then be applied to obtain high density materials. However, when intermetallic-based materials are concerned, high temperature and pressure are required to achieve compacts with high density and good mechanical properties [1]. In this study we propose the combination of MA, sputtering (PVD technique) and HIP to produce intermetallic matrix composites with improved mechanical properties. Although sputtering has been traditionally used for the coating of bulk structural components with the aim of increasing the surface properties (e.g. hardness, wear resistance, corrosion and oxidation resistance, among others) we suggest in this study the use of this technique for powder surface modification (incorporation of a second

\footnotetext{
* Corresponding author. Tel.: +351 239 790795; fax: +351 239790701.

E-mail address: bruno.trindade@ dem.uc.pt (B. Trindade).
}

phase on the surface of the particles) in order to increase the sintering ability of the mechanically alloyed particles as well the mechanical properties of the compacts after HIP.

\section{Experimental}

A $\mathrm{TiH}_{2}-48 \mathrm{Al}$ mixture consisting of $\mathrm{TiH}_{2}(99.0 \%$ purity) and $\mathrm{Al}(99.5 \%$ purity) powders (Fig. 1) was mechanically alloyed (MA'ed) in a planetary ball mill for $50 \mathrm{~h}$ using hardened steel vial and 15 balls of $20 \mathrm{~mm}$ diameter. The milling procedure was interrupted each $15 \mathrm{~min}$, for $10 \mathrm{~min}$, to cool down the system. A ball-to-powder weight ratio of 20:1 was chosen and the milling intensity was adjusted to $200 \mathrm{rpm}$. In order to avoid contamination, milling was performed in a hydrogenated argon atmosphere $\left(5 \% \mathrm{H}_{2}\right)$ and was interrupted after selected times to take out small amounts of powder for analysis.

The MA'ed powders were then coated by $\mathrm{Ti}$ and $\mathrm{Ag}$ by dc magnetron sputtering with specific discharge powers of $2.2 \times 10^{-2}$ and $1.1 \times 10^{-2} \mathrm{~W} / \mathrm{mm}^{2}$ for 90 and $60 \mathrm{~min}$, respectively. The depositions were performed in a pure argon atmosphere $(0.5 \mathrm{~Pa})$ after the chamber had been evacuated down to a base pressure of $10^{-4} \mathrm{~Pa}$. During the depositions the powders were continually shaken by vibration and translation movements in order to obtain homogeneous coatings.

Particle size distributions were determined by laser scattering (Cilas 1064 equipment) from a powder suspension in water under mechanical agitation after a 60 -s sonication.

The MA'ed powders, with and without subsequent coating, were cold isostatic pressed at $320 \mathrm{MPa}$ and then encapsulated in steel cans lined with Ta foil, degassed at $300^{\circ} \mathrm{C}$ for $60 \mathrm{~min}$ and sealed. The selected HIP cycle consisted of a cold pressurization to about $70 \mathrm{MPa}$, followed by continuous heating 


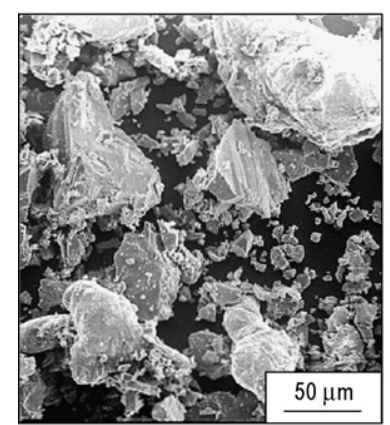

(a)

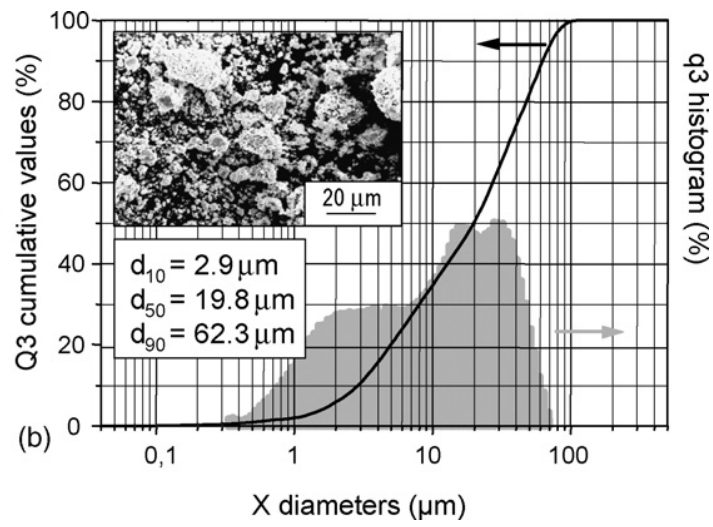

Fig. 1. (a) Morphology of the initial mixture and (b) particle size distribution after $50 \mathrm{~h}$ milling.

$(10 \mathrm{~K} / \mathrm{min})$ and pressing $(2 \mathrm{MPa} / \mathrm{min})$. The samples were consolidated at a maximum pressure of $150 \mathrm{MPa}$ for $2 \mathrm{~h}$. Cooling and decompression of the vessel were performed simultaneously. Finally the compacts were heat treated at $1200^{\circ} \mathrm{C}$ for $4 \mathrm{~h}$ in vacuum for microstructure homogenization. The cylindrical bars were cut, ground and polished with diamond down to $3 \mu \mathrm{m}$ for microstructural characterization.

The milled powders and hot-consolidated samples were analyzed using by the following techniques: X-ray diffraction (XRD) with $\mathrm{Cu} \mathrm{K} \alpha$ radiation and field emission scanning electron microscopy (SEM) with energy-dispersive $\mathrm{X}$ ray spectroscopy (EDS) analysis. The hardness and Young's modulus were calculated with a 4.9 and $0.5 \mathrm{~N}$ load, respectively, according to the method described in [2]. The fracture toughness $K_{\mathrm{c}}$ was also determined by Vickers indentation with a $294.2 \mathrm{~N}$ maximum load using the "halfpenny" and Palmqvist crack systems and the Evans et al. and Shetty et al. equations, respectively [3].

\section{Results}

\subsection{Mechanical alloying}

Fig. 1 shows the morphology of the $\mathrm{TiH}_{2}-48 \mathrm{Al}$ mixture before and after $50 \mathrm{~h}$ milling as well the particle size distribution after milling. A very broad distribution with a $d_{50}$ value of $19.8 \mu \mathrm{m}$ was obtained for the mixture milled for $50 \mathrm{~h}$ as opposed to $60.1 \mu \mathrm{m}$ for the unmilled one. This means that fracture pre- dominated over cold welding as a consequence of the presence of a brittle component $\left(\mathrm{TiH}_{2}\right)$ in the mixture.

Fig. 2 shows a series of X-ray diffraction (XRD) patterns indicating the structural evolution of the $\mathrm{TiH}_{2}-48 \mathrm{Al}$ powder mixture as a function of milling time. As can be seen, during MA the XRD peaks of the $\mathrm{TiH}_{2}$ and fcc-Al phases become broader and less intense as the result of the decrease of their structural range order. For $50 \mathrm{~h}$ milling the corresponding XRD pattern reveals the co-existence of $\mathrm{TiH}_{2}$, fcc-Al, $\mathrm{L}_{12}-\mathrm{TiAl}_{3}$ and amorphous phases, as shown by its deconvolution in the region $25^{\circ}<2 \theta<55^{\circ}$ (Fig. 2(b)).

The formation of the $\mathrm{L} 12-\mathrm{TiAl}_{3}$ phase means that a partial decomposition of the $\mathrm{TiH}_{2}$ phase occurred during milling. Taking into account the chemical composition of the mixture and the $\mathrm{Ti}-\mathrm{Al}$ phase diagram, one might say that the $\mathrm{L}_{12}-\mathrm{TiAl}_{3}$ phase is metastable. Similar results were obtained by Klassen et al. [4] and Zhang [5] for Ti-75Al (at.\%) alloys. Skakov [6] also mentions the formation of the $\mathrm{L}_{12}-\mathrm{TiAl}_{3}$ phase during $\mathrm{MA}$ of a Ti-75Al (at.\%) powder mixture doped with $\mathrm{Cr}$.

Finally, the formation of an amorphous phase observed in this study is in accordance with other studies of the Ti-Al system [7]. Theoretically, two conditions must be validated so that the amorphization of a MA mixture might occur: (i) negative enthalpy of

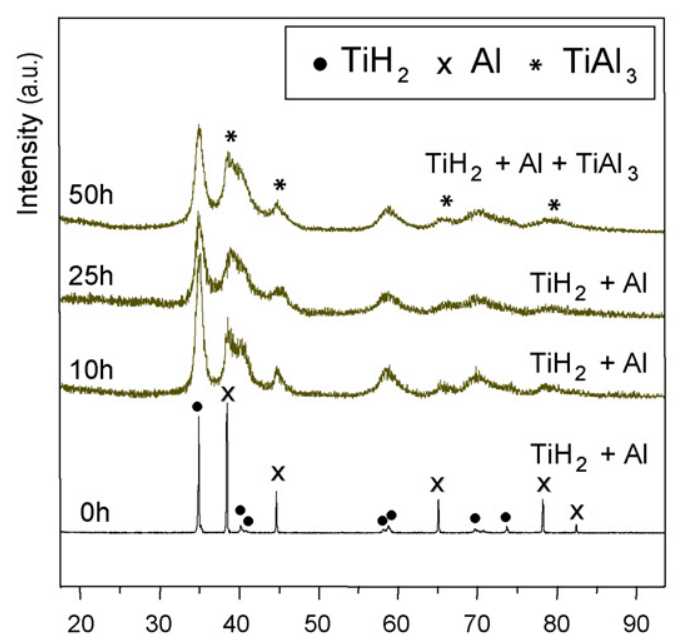

(a)

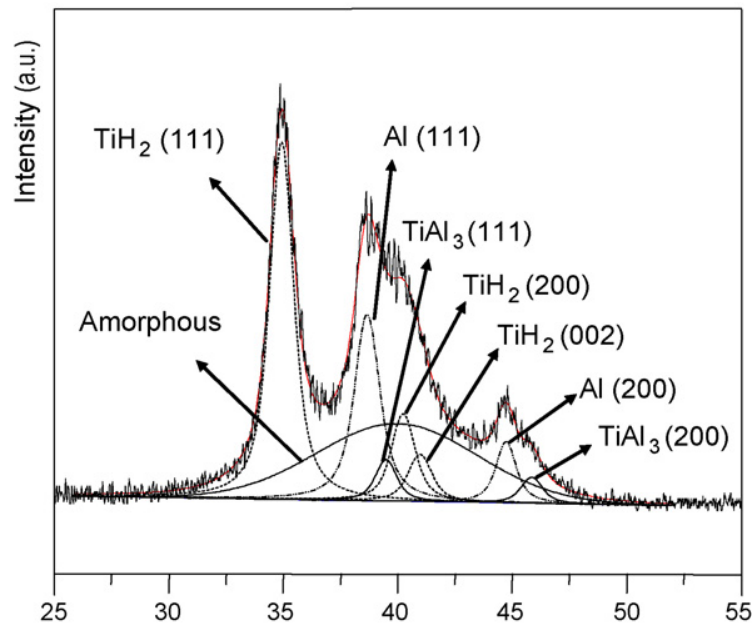

(b)
$2 \theta$

Fig. 2. (a) XRD patterns for different milling times and (b) deconvolution of the XRD pattern of the $50 \mathrm{~h}$ milled mixture. 

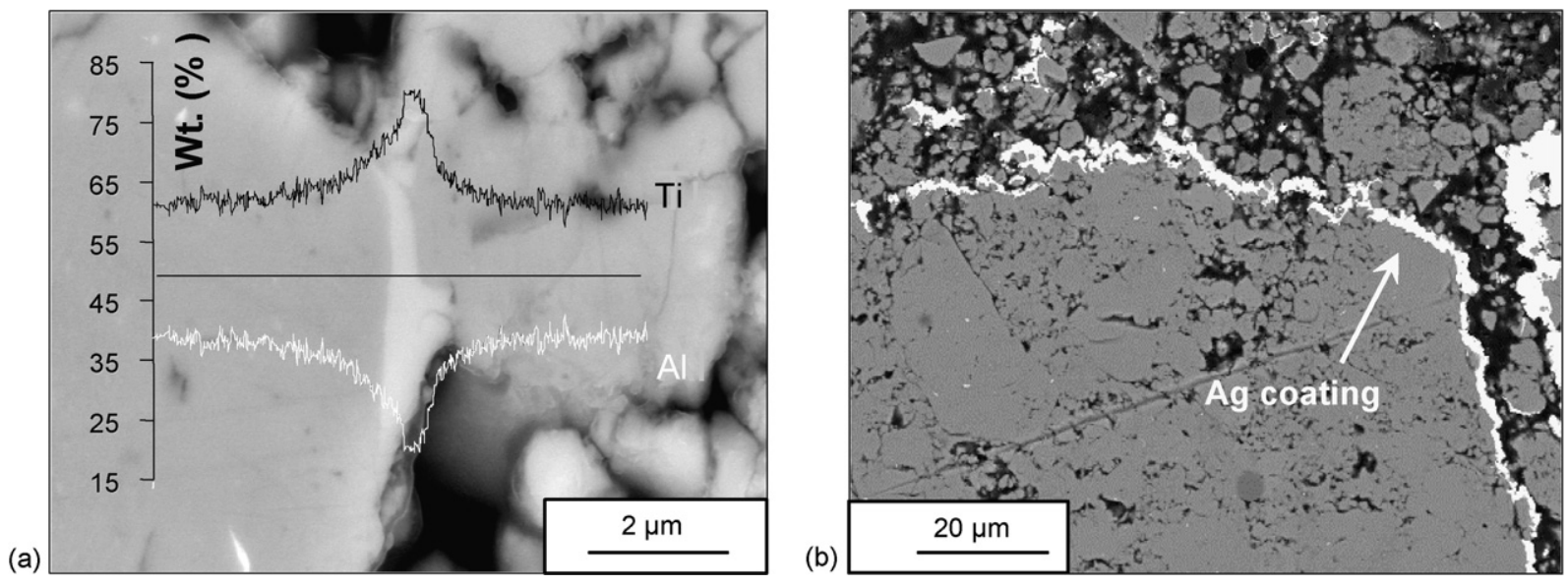

Fig. 3. SEM-BE images of the powders coated with (a) Ag and (b) Ti.

mixing and (ii) high diffusivity of one of the elements in the other element or phase. These conditions are accomplished in the system Ti-Al. The formation of any Ti-Al intermetallic is exothermal in signal and the diffusion coefficient of $\mathrm{Al}$ in the $\alpha$-Ti is much higher than the one of Ti in the fcc-Al phase $\left(1.06 \times 10^{-21}\right.$ and $2.9 \times 10^{-23} \mathrm{~cm}^{2} \mathrm{~s}^{-1}$ at room temperature, respectively [8]).

\subsection{Powders deposition}

Fig. 3 shows SEM images (BSE mode) of the mechanically alloyed $\mathrm{TiH}_{2}-48 \mathrm{Al}$ mixtures coated with $\mathrm{Ag}$ and $\mathrm{Ti}$.

Once in the $\mathrm{TiH}_{2}-48 \mathrm{Al}+\mathrm{Ti}$ system, the Ti element is present in the coating and in the MA particles, the SEM images are less illustrative than the ones obtained for the system with Ag. The Ti coating is not perceptible. Therefore, in the first case, a semiquantitative chemical analysis (EDS) was performed along a line crossing two particles. The results clearly show the presence of the coating in both systems, thicker in the $\mathrm{TiH}_{2}-48 \mathrm{Al}+\mathrm{Ag}$ system. This is not a surprising result since the sputtered yield of $\mathrm{Ag}$ is much higher that of Ti (3.1 and 0.5 atoms/ion, respectively, in an argon atmosphere and at $500 \mathrm{eV}$ [9]).

\subsection{Hot isostatic pressing}

The XRD patterns of the compacts are illustrated in Fig. 4. These consist mainly of $\gamma$-TiAl and $\mathrm{Ti}_{2} \mathrm{AlN}$ phases, the peaks of this last phase being of greater intensity in the Ag containing sample, and vestiges of the $\mathrm{Al}_{2} \mathrm{O}_{3}$ phase. It is likely that the formation of the $\gamma$-Ti-Al phase followed from the $\mathrm{TiAl}_{3}$ phase according to the equation:

$\mathrm{Al}_{3} \mathrm{Ti}+2 \mathrm{TiH}_{2} \rightarrow 3 \mathrm{TiAl}+2 \mathrm{H}_{2}$

(a)

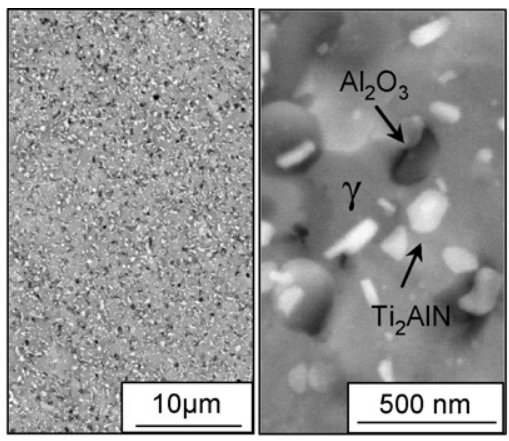

(b)

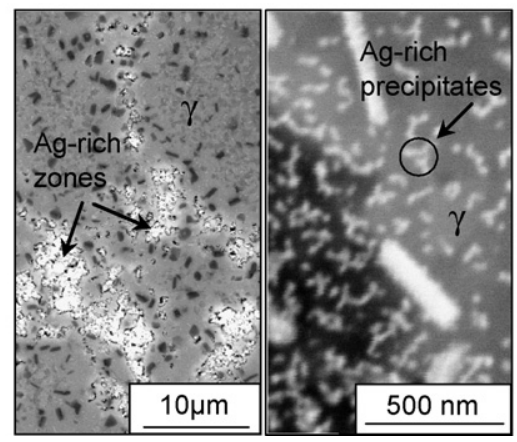

(c)

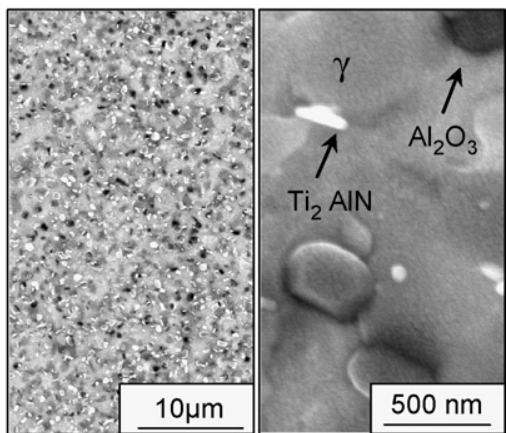

Fig. 4. XRD patterns of the hot-consolidated samples. 


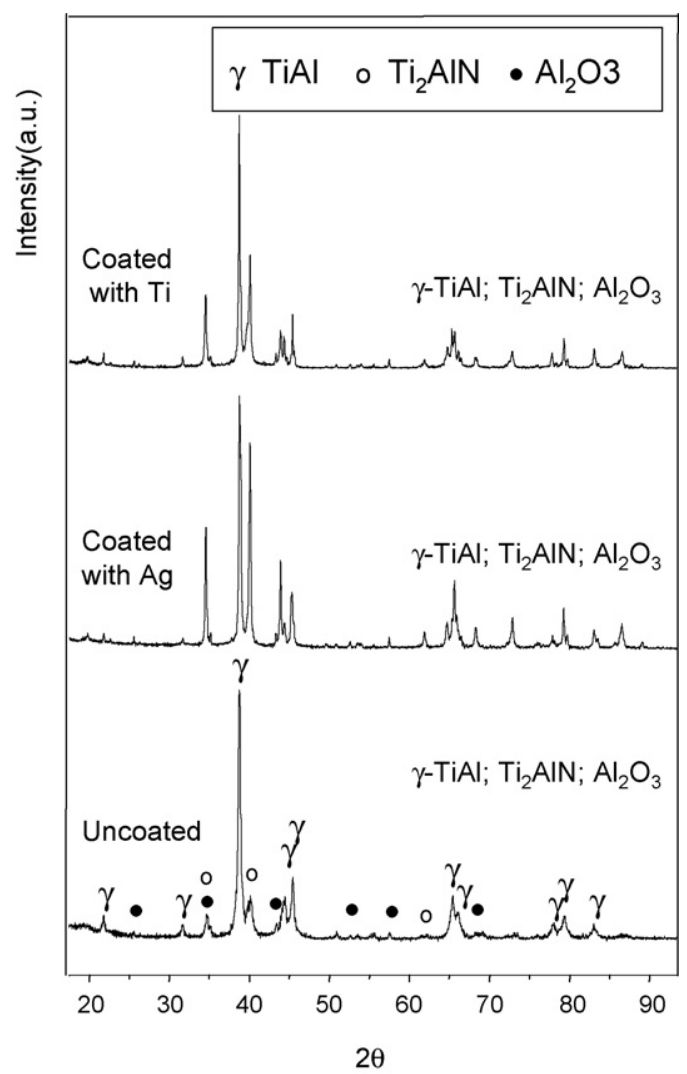

Fig. 5. SEM-BE images of the hot-consolidated samples. (a) $\mathrm{TiH}_{2}-48 \mathrm{Al}$, (b) $\mathrm{TiH}_{2}-48 \mathrm{Al}+\mathrm{Ag}$ and (c) $\mathrm{TiH}_{2}-48 \mathrm{Al}+\mathrm{Ti}$.

According to the $\mathrm{Ti}-\mathrm{Al}$ phase diagram, the samples produced in this study should have a $\gamma$-TiAl $+\alpha_{2}$-TiAl structure, the $\gamma$ phase being the main phase. However, a Ti 2 AlN nitride was detected instead of the $\alpha_{2}-\mathrm{Ti}_{3} \mathrm{Al}$ phase, which means that contamination occurred during the synthesis process. Shagiev et al. [10] also refer the formation of this nitride in a $\mathrm{Ti}-47 \mathrm{Al}-3 \mathrm{Cr}$ alloy produced by mechanical alloying and subsequent HIP at $975^{\circ} \mathrm{C}$, suggesting that it might be a variation of the $\alpha_{2}-\mathrm{Ti}_{3} \mathrm{Al}$ phase resulting from its degradation with temperature.

Fig. 5 shows SEM-BSE micrographs of the compacted samples. They are characterized by non-conventional very fine microstrutures with some precipitates in the matrix. It can be concluded from the EDS elemental X-ray maps that the white precipitates (plate-shape) are rich in titanium and nitrogen and might correspond to the $\mathrm{TiAlN}_{2}$ phase whilst the darker precipitates are Al- and O-rich, probably associated to the $\mathrm{Al}_{2} \mathrm{O}_{3}$
Table 1

Hardness and Young's modulus of the hot-consolidated and heat treated samples

\begin{tabular}{llll}
\hline & $\mathrm{TiH}_{2}-48 \mathrm{Al}$ & & \\
\cline { 2 - 4 } & Uncoated & Coated with Ag & Coated with Ti \\
\hline $\mathrm{H}(\mathrm{GPa})$ & $5.5 \pm 0.1$ & $4.4 \pm 0.1$ & $4.5 \pm 0.1$ \\
$\mathrm{E}(\mathrm{GPa})$ & $176 \pm 7$ & $182 \pm 8$ & $193 \pm 6$ \\
\hline
\end{tabular}

phase. In the Ag containing sample nanometric precipitates corresponding to an Ag-rich phase (white color) were also detected. They were not detected by XRD analysis. As referred by Suryanarayana [11] the presence of small amounts of second phases with small particle sizes cannot be easily detected by X-ray diffraction techniques. For instance, while $2 \mathrm{wt} . \%$ of Ti can be easily detected if the particle size is in the range of $26-38 \mu \mathrm{m}$, one requires about $25 \mathrm{wt} . \% \mathrm{Ti}$ if the particle size is in the range of $0.05-1.0 \mu \mathrm{m}$. Thus, a much larger amount of material is required when the particle size is in the sub-micron range.

\subsection{Heat treatment}

After HIP the samples were heat treated in a vacuum furnace at $1200^{\circ} \mathrm{C}$ for $4 \mathrm{~h}$. This led neither to significant differences in the microstructure nor in the structure of the compacts. The only feature to note was the appearance of some XRD peaks of the $\alpha_{2}$-Ti3Al phase.

\subsection{Mechanical properties}

Table 1 shows the hardness and the Young's modulus of the heat treated compacts. The values obtained do not differ significantly, however they are slightly higher than those expected for conventional Ti-48Al alloys [12]. This must be the result of the fine microstructure and grain size of the compacts, characteristic of mechanically alloyed materials.

Indentation fracture toughness analysis revealed two different situations (Fig. 6). For the applied loads in this work, no cracks were detected in the indentations of the coated samples, which is an indication of high fracture toughness. With respect to the uncoated sample, besides the cracks in the corners indentation, cracks along the edges were also detected which impeded the use of the $K_{\mathrm{c}}$ determination methods. Therefore, it is possible to affirm that the coating of the $\mathrm{TiH}_{2}-48 \mathrm{Al}$ powders synthesized by SM increases fracture toughness. (a)

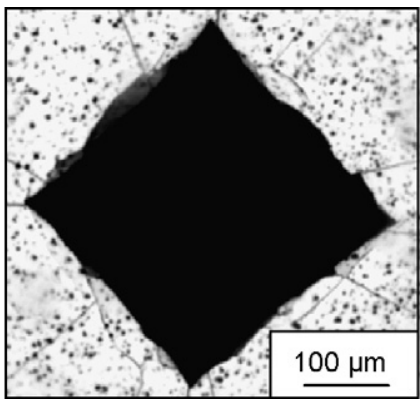

(b)

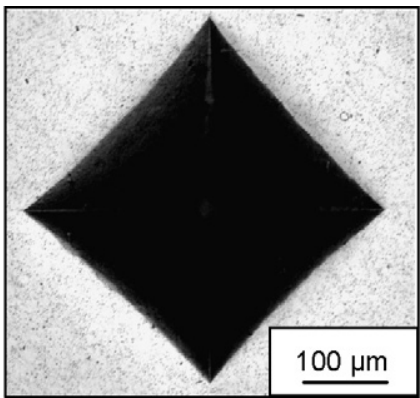

(c)

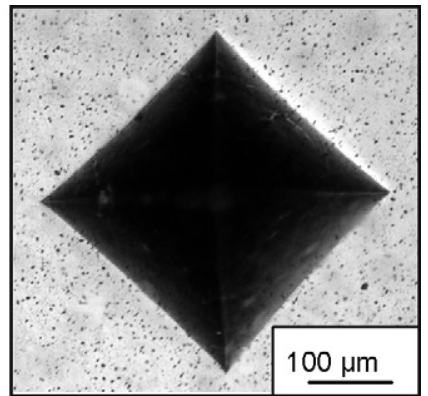

Fig. 6. Vickers indentations in the hot-consolidated and heat treated samples. (a) $\mathrm{TiH}_{2}-48 \mathrm{Al}$, (b) $\mathrm{TiH}_{2}-48 \mathrm{Al}+\mathrm{Ag}$ and (c) $\mathrm{TiH}_{2}-48 \mathrm{Al}+\mathrm{Ti}$. 


\section{Conclusions}

Magnetron sputtering was used to deposit thin layers of $\mathrm{Ag}$ and $\mathrm{Ti}$ on mechanical alloyed $\mathrm{TiH}_{2}-48 \mathrm{Al}$ particles. The results showed that the combined used of MA, sputtering and HIP might be an alternative method for the synthesis of compacts with non-conventional microstructures formed by surface modified intermetallic particles. Young's modulus and fracture toughness of the TiAl-based compacts were improved by the deposition of an $\mathrm{Ag}$ or Ti thin layer on the mechanically alloyed powders.

\section{Acknowledgments}

The authors gratefully acknowledge the financial support from Portuguese Foundation for Science and Technology (FCT) thought project POCTI/CTM/46498/2002.

\section{References}

[1] G.-X. Wange, M. Dahms, Powder Metall. 24 (1992) 219-225.

[2] J.M. Antunes, A. Cavaleiro, L.F. Menezes, M.I. Simões, J.V. Fernandes, Surf. Coat. Technol. 149 (2002) 27-35.

[3] C.B. Ponton, R.D. Rawlings, Mater. Sci. Technol. 5 (1989) 865-872.

[4] T. Klassen, M. Oehring, R. Bormann, Acta Mater. 45 (9) (1997) 3935 3948.

[5] F. Zhang, L. Lu, M.O. Lai, J. Alloys Compd. 297 (2000) 211-218.

[6] A. Skakov, J. Met. Nanocrys. Mater. 8 (2000) 597-602.

[7] M. Bououdina, J. Met. Nanocryst. Mater. 12 (2002) 9-17.

[8] L. Lü, M.O. Lai, Mechanical Alloying, Kluwer Academic Publisher, 1998.

[9] J.L. Vossen, J.J. Cuomo, in: J.L. Vossen, W. Kern (Eds.), Thin Films Processes, Academic Press, 1978.

[10] M.R. Shagiev, O.N. Senkov, G.A. Salishchev, F.H. Froes, J. Alloys Compd. (2000) 201-208

[11] C. Suryanarayana, Prog. Mater. Sci. 46 (2001) 1-184.

[12] Y.-W. Kim, JOM (1994) 30-39. 